\title{
A comparative study of two layer versus three-layer repair of mediolateral episiotomy
}

\author{
Manasi V. Gaikwad ${ }^{1 *}$, M. Vijaya Sree ${ }^{1}$, Swapnil V. Bobde ${ }^{2}$
}

\begin{abstract}
${ }^{1}$ Department of Gynaecology, Mamata Medical College, Khammam, Telangana, India
${ }^{2}$ Department of Urology, Mamata Medical College, Khammam, Telangana, India
\end{abstract}

Received: 11 June 2020

Accepted: 08 July 2020

\section{*Correspondence:}

Dr. Manasi V. Gaikwad,

E-mail: manasigyn@gmail.com

Copyright: () the author(s), publisher and licensee Medip Academy. This is an open-access article distributed under the terms of the Creative Commons Attribution Non-Commercial License, which permits unrestricted non-commercial use, distribution, and reproduction in any medium, provided the original work is properly cited.

\begin{abstract}
Background: Since majority of the women attending study hospital are belonging to lower socioeconomic strata and active involvement of paramedical staff in providing obstetric care, this study was undertaken to find the utility of a two-layer repair of mediolateral episiotomy and compare it with the standard method of closure in relation to its simplicity, cost-effectiveness and superiority if any, over the traditional three-layered repair of episiotomy.

Methods: This was a prospective interventional study comparing 100 women who underwent two-layer closure with 100 women who underwent three-layer closure of episiotomy in a tertiary care hospital in Pune, India over a period of 2 years from October 2012 to October 2014. The parameters assessed were operative time, number of suture materials required, immediate post procedure pain and complications at follow-up. Qualitative and quantitative data was analysed using unpaired t-test, chi square test and Fisher exact test.

Results: Both the groups were comparable in terms of hospital stay and wound complications such as oedema, dehiscence, hematoma, requirement of resuturing, cosmesis and long-term complications such as dyspareunia. However, two-layer repair required less operative time, lesser number of suture materials and decreased pain during hospital stay as there was statistically significant difference observed between the two groups.

Conclusions: In this study experience, it can be concluded that two-layer repair of episiotomy is faster, with less postoperative pain and more cost effective. Hence it provides mother with better services.
\end{abstract}

Keywords: Continuous, Episiotomy, Interrupted, Mediolateral, Three-layer, Two-layer

\section{INTRODUCTION}

Episiotomy is a surgically planned incision on the perineum and posterior vaginal wall during the second stage of labour. Amongst $85 \%$ pregnant women giving birth vaginally, $60 \%$ will have wound to be sutured. ${ }^{1}$ Mediolateral episiotomy has proven its role in preventing anterior and posterior perineal trauma., ${ }^{2,3}$ There are repeated evidences suggesting that continuous suturing of episiotomy is far less painful and also saves time by equally distributing the tension in the suture due to oedema. ${ }^{4,5}$ Here the skin is sutured by subcuticular stitch. In India due to large prevalence of women from low socioeconomic strata along with active involvement of paramedical staff, the technique has to be simplified. Therefore, authors explored two-layer repair technique whereby the muscle and mucosa were sutured in continuous manner and skin with vertical mattress suture.

Hence, with an objective of evaluating two-layer repair for pain perception, operative time, wound healing and complications, authors undertook a comparative study at a tertiary care hospital in Pune, India.

\section{METHODS}

A total 200 antenatal women were included in this study and they were divided into two groups. 
- Group A: Hundred cases of two-layer repair of episiotomy.

- Group B: Hundred cases of three-layer repair of episiotomy.

All patients in both groups gave consent in writing prior to recruitment in the study. Approval of the institutional ethics committee was taken beforehand.

All patients who fulfilled the inclusion criteria were subjected to detailed history taking, thorough general, systemic and obstetric examination.

\section{Inclusion criteria}

- A gravid patient of any parity following: full term vaginal delivery, singleton pregnancy, vertex presentation, mediolateral episiotomy.

\section{Exclusion criteria}

- Instrumental delivery, haemoglobin $<8$ gm\%, body mass index $>25 \mathrm{~kg} / \mathrm{m}^{2}$, pre-existing medical disorder like heart disease, pre-eclampsia and renal disease, Third degree or fourth degree vaginal tear.

In all patients after thorough cleaning of perineum with antiseptic solution under local anaesthesia, mediolateral episiotomy was given on left side at crowning of vertex. After the expulsion of placenta, suturing was initiated using chromic catgut number 1 with half circle needle due to easy availability and ease of taking vaginal mucosa and muscle together in single stitch.
Technique of two-layer repair of episiotomy in Group A: - starting $1 \mathrm{~cm}$ proximal to the episiotomy apex, vaginal mucosa and muscle was stitched together in continuous manner and knot was tied at mucocutaneous junction.

Technique of three-layer repair of episiotomy in Group B: starting $1 \mathrm{~cm}$ proximal to the episiotomy apex, vaginal mucosa and submucosa were reapproximated in a continuous locking fashion and muscle tissue with interrupted sutures. Skin was closed in vertical mattress sutures in both the groups and haemostasis was confirmed. Standard institutional antibiotic protocols were followed in both the groups. Daily assessment of the patients till day 3 after procedure was done. Patients perceiving pain moderate or greater than moderate on visual analogue scale that is score 4 or more were recorded as presence of pain (Figure 1). After discharging on $3^{\text {rd }}$ day, they were followed up at 6 weeks in OPD to look for dyspareunia, as generally by this time most have had resumed their sexual activity and it was easier for them to follow-up at that time due to subsequent immunisation of the baby.

\section{RESULTS}

Parameters such as duration of suturing, hospital stay, pain, number of sutures required, complications during hospital stay and at follow-up were analysed in both the groups (Table 2, 3, 4).

Patients of both the groups were comparable in terms of demographic and clinical characteristics which have been presented (Table 1).

Table 1: Demographic and clinical parameters of patients.

\begin{tabular}{|c|c|c|c|}
\hline & $\begin{array}{l}\text { Group A (study group) } \\
\mathbf{N}=100\end{array}$ & $\begin{array}{l}\text { Group B (control group) } \\
\mathbf{N}=100\end{array}$ & $\begin{array}{l}\text { p value (using unpaired } t \\
\text { test) }\end{array}$ \\
\hline Age & $25 \pm 2.6$ & $24.55 \pm 2.5$ & $0.318^{*}$ \\
\hline Body mass index & $22.22 \pm 1.08$ & $22.45 \pm 1.3$ & $0.186^{*}$ \\
\hline Haemoglobin $(\mathrm{gm} \%)$ & $9.58 \pm 0.627$ & $9.75 \pm 0.79$ & $0.095^{*}$ \\
\hline Baby birth weight (grams) & $2640 \pm 361.11$ & $2599 \pm 332.3$ & $0.410^{*}$ \\
\hline \multirow{2}{*}{ Parity } & One $\quad$ Two & One & \multirow{2}{*}{$0.885^{* \#}$} \\
\hline & 60 & 38 & \\
\hline
\end{tabular}

*Not significant, \# using chi square test.

Table 2: Comparison of operative time and hospital stay.

\begin{tabular}{|llll|}
\hline & $\begin{array}{l}\text { Group A (study } \\
\text { group) } \mathbf{N = 1 0 0}\end{array}$ & $\begin{array}{l}\text { Group B (control } \\
\text { group) N=100 }\end{array}$ & $\begin{array}{l}\text { p value (using } \\
\text { unpaired t-test) }\end{array}$ \\
\hline Duration of episiotomy (in minutes) & $9.37 \pm 1.02$ & $15.73 \pm 1.63$ & $<0.001$ (significant) \\
\hline Duration of hospital stay (Number of days) & $3 \pm 0.0$ & $3.36 \pm 2.05$ & 0.083 (not significant) \\
\hline
\end{tabular}

It was noted that two-layer repair of episiotomy took 9.37 minutes as compared to 15.73 minutes in Group B which was statistically significant with $\mathrm{p}$ value of less than 0.001 (Table 2). 
Similarly, number of suture materials required that is mean number of packets used were 1.01 in Group A while 1.2 in Group B with p value of 0.045 and hence significant result (Table 3).

Statistically significant difference was also observed in immediate post procedure pain perception which was lesser in Group A than in Group B with p value of 0.037 . Overall, from Group B two episiotomies gaped which was defined as more than $50 \%$ separation of the mucosa and/or deeper separation and one episiotomy from the same group had hematoma formation. So, all 3 episiotomies from Group B needed resuturing (Table 4). Which increased the mean hospital stay 3.36 days as compared to 3 days in Group A but this was statistically not significant ( $\mathrm{p}$ value 0.083 ) (Table 2).

At 6 weeks follow up, patients from both groups were comparable with each other with respect to complications. One patient from Group A and 4 patients from Group B had pain at the suture site, which was not statistically significant (Table 4). None of the patients had experienced dyspareunia, painful defecation or an unsightly scar.

Table 3: Number of suture materials required.

\begin{tabular}{|lllll|}
\hline Group A (study group) $\mathbf{N}=\mathbf{1 0 0}$ & Group B (control group) $\mathbf{N}=\mathbf{1 0 0}$ & p value (using chi square test) \\
\cline { 1 - 2 } One packet & Two packets & One packet & Two packets & \multirow{2}{*}{0.045 (significant) } \\
\hline 91 & 9 & 80 & 20 &
\end{tabular}

Table 4: Immediate post-procedure complications and at follow-up.

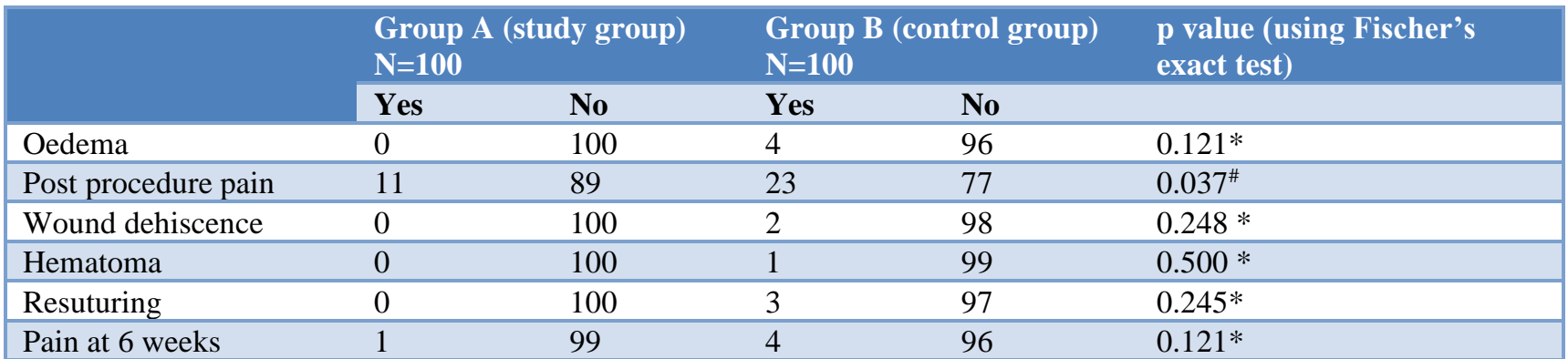

*Not significant, \#Statistically significant.

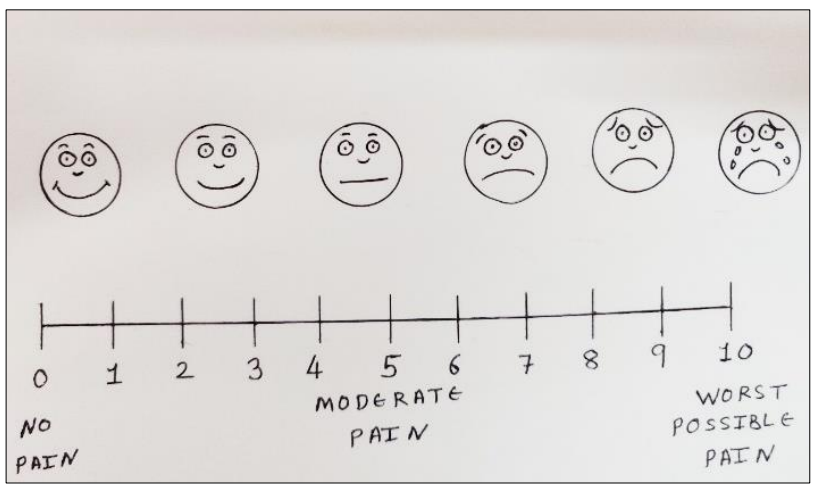

Figure 1: Visual analogue scale.

\section{DISCUSSION}

As the role of surgeon superseded that of midwifes in obstetrics, the perineum became the site of surgical intervention that is episiotomy. At first it was the occasional practice but later on became the most common form of obstetric surgery affecting millions of women throughout the world and can result in long term maternal morbidity. ${ }^{6}$ In this context, in present study two-layer repair of episiotomy was studied, analysed and compared with standard literature.

As the study was related to child birth, it is natural that the women in reproductive age group were selected, so the mean age of participants was 25 years in both the groups. The mean body mass index in present study was $22 \mathrm{~kg} / \mathrm{m}^{2}$ in both the groups.

According to Anaya DA et al obese people face more problems in wound healing due to oxidative stress created by excess adipose tissue. ${ }^{7}$ Thus overweight which is body mass index more than $25 \mathrm{~kg} / \mathrm{m}^{2}$ was excluded as a limiting factor for healing from present study. Mean haemoglobin in both the groups was $9.5 \mathrm{gm} \%$.

According to Bishops A et al, haemoglobin more than 8 gm\% is crucial for optimum wound healing. ${ }^{8}$ Thus patients with less than $8 \mathrm{gm} \%$ haemoglobin was excluded from the present study to avoid bias.

Mean time required for suturing episiotomy in two layers in the present study in Group A was very much shorter 
than that in Group B which was highly significant ( $p$ value less than 0.001 ).

Similar results were obtained by Shirin Hasnapoor where mean time in continuous repair was 5.34 minutes whereas in interrupted repair it was 6.54 minutes and $p$ value less than 0.001.9 very recently in March 2020 in Madrid, Spain, Carolina López-Lapeyrert et al also published the similar findings stating continuous repair of second degree tear of perineum takes less time than that of interrupted repair. ${ }^{10}$

According to Zafar S, randomized control trial, interrupted sutures take more time requiring more thread as time and suture material is wasted every time a knot is tied and thread is cut. ${ }^{11}$ The mean number of suture material required in Group A was significantly less than in Group B (p value 0.045). Shirin Hasnapoor and Valenzuela $\mathrm{P}$ et al also confirmed this finding in their randomized control trial in 2012 and 2009 in Pakistan and Spain respectively. ${ }^{9,12}$ Immediate post procedure pain perception in Group A was significantly less than that of Group B (p value 0.037). Kettle $\mathrm{C}$ et al, confirmed this finding in 7 randomized control trials conducted in 4 countries involving 3822 women. ${ }^{13}$

The increased pain perception in interrupted sutures maybe due to restriction in the distribution of tissue oedema due to possibility of overtightening the stitches, while in continuous sutures the tissue tension spreads equally along the suture line. Not long ago similar findings were also observed by Martínez-Galiano JM et al, in their randomized controlled trial on continuous versus discontinuous suturing of postpartum perineal injuries. ${ }^{14}$ With respect to tissue dehiscence both the techniques were comparable as was observed by Shirin Hasnapoor, Valenzuela P. and Kettle C. et al. ${ }^{9,12,13}$

Rich vascular network of perineum with circle of anastomosis around each orifice along with multiple perforating vessels maintaining high oxygen tension makes wound dehiscence in the perineum a rare event with accepted incidence of $0.1 \% .^{15,16}$ This study patients were assessed only till follow-up at 6 weeks so the longterm effects of the continuous two-layer repair of episiotomy on the pelvic floor weakening leading to either faecal or urinary incontinence and prolapse could not be studied.

Nevertheless, in this study experience two-layer repair of episiotomy is faster, economical and with decreased immediate post procedure pain and authors recommend it.

\section{ACKNOWLEDGMENTS}

Authors would like to thank to Dr. Bhosle RA, professor and head of the department of obstetrics and gynecology, B. J. Medical college, Pune and Dr. Girish Pote for their keen interest, inspiring guidance, constant encouragement with my work during all stages, to bring this research paper into fruition.

Funding: No funding sources

Conflict of interest: None declared

Ethical approval: The study was approved by the Institutional Ethics Committee

\section{REFERENCES}

1. Gemynthe A, Langhoff-Roos J, Sahl S, Knudsen J. New VICRYL formulation: an improved method of perineal repair?. Br J Midwife. 1996;4(5):230-4.

2. Carroli G, Belizan J. Episiotomy for vaginal birth. Cochrane Database Syst Rev. 1999;3:CD000081.

3. Kudish B, Blackwell S, Mcneeley SG, Bujold E, Kruger M, Hendrix SL, Sokol R. Operative vaginal delivery and midline episiotomy: a bad combination for the perineum. Am J Obstet Gynecol. 2006;195(3):749-54.

4. Morano S, Mistrangelo E, Pastorino D, Lijoi D, Costantini S, Ragni N. A randomized comparison of suturing techniques for episiotomy and laceration repair after spontaneous vaginal birth. J Minimal Inv Gynecol. 2006;13(5):457-62.

5. Kettle C, Hills RK, Ismail KM. Continuous versus interrupted sutures for repair of episiotomy or second degree tears. Cochrane Database Syst Rev. 2007;4:CD000947.

6. Klein M. Episiotomy and the second stage of labour. Canad Family Phys. 1988;34:2019.

7. Anaya DA, Dellinger EP. The obese surgical patient: a susceptible host for infection. Surgical infections. 2006;7(5):473-80.

8. Bishop A. Role of oxygen in wound healing. J Wound Care. 2008;17(9):399-402.

9. Hasanpoor S, Bani S, Shahgole R, Gojazadeh M. The effects of continuous and interrupted episiotomy repair on pain severity and rate of perineal repair: a controlled randomized clinical trial. J Caring Sci. 2012;1(3):165.

10. López-Lapeyrere C, Solís-Muñoz M, Hernández-López AB, Rodríguez-Barrientos R, González-Rubio R. Carol research group. Perineal repair of media-lateral episiotomies and $2^{\text {nd }}$ degree tears by midwives: a randomised controlled trial comparing three suture techniques. Int J Nurs Stud. 2020;3:103553.

11. Zafar S. Comparison of a single-knot versus three layered technique of perineal repair after vaginal delivery in women requiring episiotomy: a double blind randomized controlled trial. J Turkish-German Gynecol Associat. 2008;9(3):129-30.

12. Valenzuela P, Saiz Puente MS, Valero JL, Azorin R, Ortega R, Guijarro R. Continuous versus interrupted sutures for repair of episiotomy or second-degree perineal tears: a randomised controlled trial. BJOG: An Int J Obstet Gynaecol. 2009;116(3):436-41.

13. Kettle C, Dowswell T, Ismail KM. Continuous and interrupted suturing techniques for repair of episiotomy or second-degree tears. Cochrane Database Syst Rev. 2012;11:CD000947.

14. Martínez-Galiano JM, Arredondo-López B, MolinaGarcia L, Cámara-Jurado AM, Cocera-Ruiz E, Rodríguez-Delgado M. Continuous versus discontinuous suture in perineal injuries produced 
during delivery in primiparous women: a randomized controlled trial. BMC Preg Childbirth. 2019;19(1):499.

15. Sinna R, Qassemyar Q, Benhaim T, Lauzanne $P$, Sabbagh C, Regimbeau JM, et al. Perforator flaps: a new option in perineal reconstruction. J Plast Reconst Aesth Surg. 2010;63(11):e766-74

16. Ramin SM, GILSTRAP III LC. Episiotomy and early repair of dehiscence. Clin Obstet Gynecol. 1994;37(4):816-23.
Cite this article as: Gaikwad MV, Sree MV, Bobde SV. A comparative study of two layer versus threelayer repair of mediolateral episiotomy. Int J Reprod Contracept Obstet Gynecol 2020;9:3412-6. 